\title{
Communication network structure parameters and new knowledge generation capabilities in companies engaged in industry control system engineering projects
}

\author{
Sergei Titov ${ }^{1, a}$, Sergei Suetin ${ }^{1}$, Natalya Titov ${ }^{2}$, Sergei Nikitin $^{2}$ and Nikolai Malyshkin ${ }^{2}$ \\ ${ }^{1}$ Moscow Technological Institute, 119334 Moscow, Russia \\ ${ }^{2}$ State University of Management, 109542 Moscow, Russia
}

\begin{abstract}
Engineering companies engaged in business of industry control systems need to manage the processes of generation of innovations within and across their projects. Generation and diffusion of innovations materialize through the communication networks of project teams. Therefore, it is possible to hypothesize that the characteristics of communication networks play role in generation of new knowledge. With the data from 14 industry control system projects of a Russian engineering company the communication network structure characteristics were calculated and the analysis of correlation between these characteristics and knowledge generation capabilities was performed. As a result correlation between centralization of communication and the number of new technical solutions developed in projects was discovered.
\end{abstract}

\section{Introduction}

With the advent of Internet technology in general and $\mathrm{m} 2 \mathrm{~m}$ technologies in particular [1] the industry control systems have been going through the constant change of the technological platforms. This implies the necessity to develop, disseminate and adopt new innovative solutions pertaining to the platforms, subsystems and elements of the industry control systems. The industry control system engineering is becoming extremely innovative sector of economy.

Engineering companies engaged in business of industry control systems need to manage the processes of generation of innovations within and across their projects. However, as Davies and Hobday (2005) noted [2] diffusion of innovations and knowledge generation in project-based companies are characterized by the problems of the extensive communication barriers between projects which hinder the effective dissemination of the innovative ideas and solutions across the projects of one company. Hence, the communications within and between projects can play significant role in innovation management and influence the speed and effectiveness of the diffusion of innovations.

\section{Role of communications in industry control system engineering projects}

Many researchers highlight the critical role of communications for the success of innovative engineering projects. For instance, Gupta and Wilemon
(1988) analyzed the interaction between marketing and research departments in an engineering company and found out that the quality and the structure of the communications between these two types of departments notably effected the effectiveness of the innovation projects [3]. Pinto and Pinto (1990) ascertained that the high level of cooperation between the innovative project teams accompanied by the higher probability of the project success [4]. Allen, Lee and Tushman showed that the performance of innovation projects connected with the styles and quality of communications within the project teams [5]. Jagdev and Müller (2005) [6] and Henderson (2004) [7] determined the connection between communication competencies of project team members and success of projects. Ryynanen (2012) emphasized that effective communications are especially important for knowledge-intensive engineering projects [8]. Though many authors investigated the role of communications in engineering projects, these studies were largely of conceptual rather than of empirical nature. Yet another deficiency of the current body of research on communications in engineering projects is the insufficient number of quantitative findings. The article presented is trying to compensate for the lack of empirical quantitative research in the field of communication management in control system engineering projects.

\section{Research methodology}

The research methodology consists of the calculation of the formal quantitative characteristics of the

\footnotetext{
a Corresponding author: s_titov@mti.edu.ru
} 
communication networks in industry control system engineering projects with the help of social network analysis [9] and the analysis of correlation between of these quantitative characteristics, on the one hand, and new knowledge generation capabilities of these projects.

The research hypothesis is that between quantitative structural characteristics of communication networks (such as density, average degree, centralization of a network) and knowledge generation capabilities there may be possible correlation that can be revealed with the help of statistical methods.

The research was conducted in a Russian engineering company realizing many industry control system projects. For the purposes of the research 14 different projects successfully finished in the year before the research were selected. These projects were comparable in terms of the number of team members, budgets, durations, scope and complexity of the project results.

In each of these projects the specific communication patterns evolved. These communication patterns can be described as networks consisted of vertices and arcs. Vertices represent the members of project team, and the arcs reflect the communications that can be considered as significant. The significance of the communications was defined as a frequency of the formal communications related to the problems, tasks, risks and other elements of a project within the project lifecycle. The significant communications were defined as those that occurred between project team members at least ten times every week during the project lifecycle. The data about communications (participants, frequencies) was derived from the project management information system used in the company. As a result the network models similar to one depicted in Figure 1 were constructed.

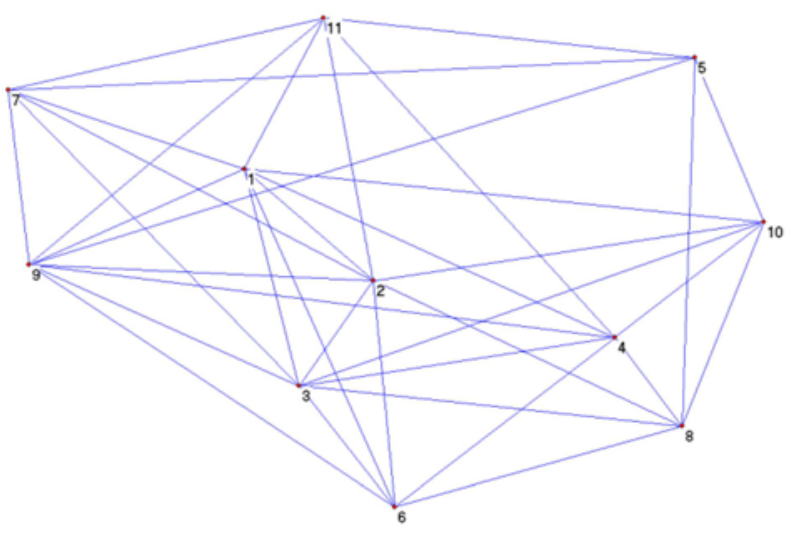

Figure 1. The sample communication network model.

For each communication network three different quantitative characteristics were calculated. These characteristics included:

- Density of the network,

- Average degree of the network,

- Degree centralization of the network.

The density and average degree measure how many significant communication links occurred in the project team communication network. The degree centralization is a measure of how the communication network are centralized.
The density of the network was calculated as:

$$
\operatorname{Den}=l / n(n-1) \text {, }
$$

where Den - density of the network, $l$ - number of the arcs in the network, $n$ - number of the vertices in the network (project team members).

The average degree of the network was found with the help of the following formula:

$$
e g=\sum_{i}^{n}\left(\operatorname{Deg}_{i}\right) / n,
$$

where $A v D e g$ - average degree of the network, $\operatorname{Deg}_{i}-$ degree (number of the links) of the vertice $i, n$ - number of the vertices (project team members).

The degree centralization was calculated with the formula:

$$
C D=\sum_{i}^{n}\left(\operatorname{Deg}_{\max }-\operatorname{Deg}_{i}\right) /(n-1)(n-2),
$$

where $C D$ - degree centralization of the network, $D e g_{\max }$ - the maximum degree in the network, $D e g_{i}$ degree of the vertice (participant) $i, n$ - number of the vertices (project team members).

Knowledge generation capabilities were defined on the basis of the information registered in the company's knowledge management systems. Many projects in the company develop new technical solutions pertaining to industry control systems. Every technical solution is analyzed by the knowledge manager and then saved in the knowledge management data base. The knowledge manager assesses the potential of the new technical solutions in terms of the possibility to be used it in other projects. Each registered technical solution therefore has its rating which reflects the potential of the solution for the future projects. Hence, the knowledge generation capabilities of the project teams can be measured by the number of the new technical solutions and the average rating. Ratings are measure on the scale from 1 to 10 where 10 is the highest possible value.

To analyze the connection between structural characteristics of the communication networks and new knowledge generation capabilities the correlation analysis procedures were conducted with the help of MiniTab software. Pearson correlation coefficients and associated p-values were calculated.

\section{Research findings}

Using the data from the corporate project management information system the network models of communications in project teams were elaborated and the quantitative structural characteristics of the networks were calculated with the formulas (1-3). The results of the calculations are shown in Table 1 .

From the knowledge management information system the number of the new technical solutions developed in the projects was derived and the average ratings of the new technical solutions were calculated. The number of the new technical solutions is provided and their average ratings of the future potential are presented in Table 2 . 
Table 1. Quantitative characteristics of the communication networks in industry control system projects.

\begin{tabular}{|c|c|c|c|c|}
\hline 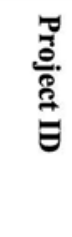 & 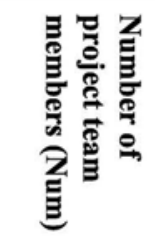 & 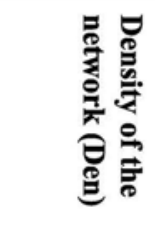 & 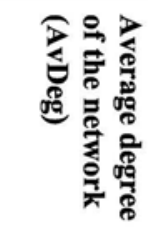 & 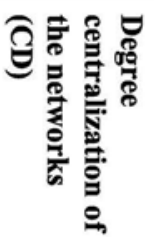 \\
\hline $\mathrm{A}$ & 14 & 0,1868 & 2,4286 & 0,2308 \\
\hline B & 11 & 0,3273 & 3,2727 & 0,2111 \\
\hline $\mathrm{C}$ & 11 & 0,6727 & 6,7273 & 0,1556 \\
\hline $\mathrm{D}$ & 9 & 0,3889 & 3,1111 & 0,6250 \\
\hline $\mathrm{E}$ & 15 & 0,2190 & 3,0667 & 0,4890 \\
\hline F & 18 & 0,1634 & 2,7778 & 0,2132 \\
\hline $\mathrm{G}$ & 13 & 0,3462 & 4,1538 & 0,1970 \\
\hline $\mathrm{H}$ & 12 & 0,2272 & 2,5000 & 0,3818 \\
\hline $\mathrm{J}$ & 17 & 0,2059 & 3,2941 & 0,3333 \\
\hline $\mathrm{K}$ & 18 & 0,1568 & 2,6667 & 0,1544 \\
\hline $\mathrm{L}$ & 10 & 0,3111 & 2,8000 & 0,7222 \\
\hline $\mathrm{M}$ & 13 & 0,4359 & 5,2308 & 0,3864 \\
\hline $\mathrm{N}$ & 12 & 0,3182 & 3,5000 & 0,6000 \\
\hline $\mathrm{O}$ & 17 & 0,1838 & 2,9412 & 0,2167 \\
\hline
\end{tabular}

Table 2. Number of the new technical solutions developed in the projects analyzed and their average ratings.

\begin{tabular}{|l|l|l|}
\hline $\begin{array}{l}\text { Project } \\
\text { ID }\end{array}$ & $\begin{array}{l}\text { Number of the new } \\
\text { technical solutions } \\
\text { developed in the } \\
\text { project (NumNew) }\end{array}$ & $\begin{array}{l}\text { Average rating of } \\
\text { the new technical } \\
\text { solutions (AvRat) }\end{array}$ \\
\hline A & 1 & 5 \\
\hline B & 2 & 6 \\
\hline C & 0 & 0 \\
\hline D & 4 & 5 \\
\hline E & 5 & 7 \\
\hline F & 1 & 6 \\
\hline G & 0 & 0 \\
\hline H & 2 & 5 \\
\hline J & 2 & 3 \\
\hline K & 1 & 5 \\
\hline L & 4 & 6 \\
\hline M & 2 & 4 \\
\hline N & 3 & 6 \\
\hline O & 0 & 0 \\
\hline
\end{tabular}

The correlation between each of the quantitative structural characteristics of the project communication networks, on the one hand, and two measures of the new knowledge generation capabilities was analyzed by calculating Pearson correlation coefficients and p-values. The results are shown in Table 3 .
Table 3. Pearson correlation coefficients and p-values (in brackets).

\begin{tabular}{|c|c|c|c|c|}
\hline $\begin{array}{l}\text { Knowledge } \\
\text { generation } \\
\text { capability } \\
\text { metrics }\end{array}$ & 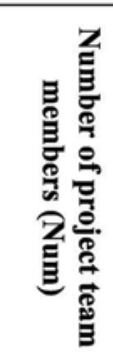 & 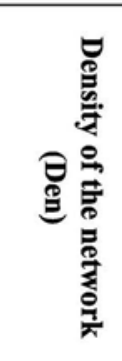 & 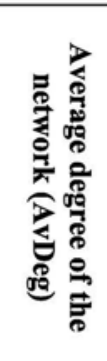 & 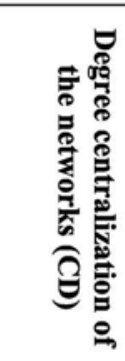 \\
\hline $\begin{array}{l}\text { Number of the } \\
\text { new technical } \\
\text { solutions } \\
\text { developed in } \\
\text { the project } \\
\text { (NumNew) }\end{array}$ & $\begin{array}{c}-0,377 \\
(0,184)\end{array}$ & $\begin{array}{c}-0,083 \\
(0,777)\end{array}$ & $\begin{array}{l}-0,306 \\
(0,288)\end{array}$ & $\begin{array}{c}0,860 \\
(0,000)\end{array}$ \\
\hline $\begin{array}{l}\text { Average } \\
\text { rating of the } \\
\text { new technical } \\
\text { solutions } \\
\text { (AvRat) }\end{array}$ & $\begin{array}{c}-0,085 \\
(0,772)\end{array}$ & $\begin{array}{c}-0,394 \\
(0,164)\end{array}$ & $\begin{array}{c}-0,552 \\
(0,041)\end{array}$ & $\begin{array}{c}0,504 \\
(0,066)\end{array}$ \\
\hline
\end{tabular}

The correlation between the number of the new technical solutions developed in projects and the degree centralization of the project communication network can be considered as high with Pearson coefficient 0,860 and $\mathrm{p}$-value 0,000 . The weak correlation is found between the average new technical solution ratings and the average degree of the networks with Pearson coefficient 0,552 and $\mathrm{p}$-value 0,041 . The correlation between the average new technical solution ratings and the degree centralization of the networks can be also considered as weak (Pearson coefficient $-0,504$ and p-value 0,066). Other results cannot be considered as statistically significant.

\section{Interpretation of research findings}

The most notable and interesting result of the research is the high correlation between the new technical solutions developed in the company projects and the degree centralization of the project communications networks. The more centralized is the communication network the more new technical solutions related to industry control systems were developed. Of course, the correlation is now causation. But it is clear that centralization of communications plays significant role in new technical knowledge generation. In order to investigate further in the nature of the relationship between centralization of project communications and knowledge generation capabilities additional research is needed.

However, even from the research presented in this article and based on the data limited to the several projects from the only one engineering company we can recommend to stimulate the development of the more centralized communications in the industry control system project if there is a need for new technical solutions. 


\section{References}

1. S. Krishnamurthy, O. Anson, L. Sapir, C. Glezer, M. Rois, I. Shub and K. Schloeder, The Internet of Things, First International Conference, IOT, pp, 68$86(2008)$

2. A. Davies and M. Hobday, The Business of Projects: Managing Innovation in Complex Products and Systems (Cambridge University Press, 2005)

3. A.K. Gupta and D. Wilemon, J Prod Innovat Manag, 5, 20 (1988)

4. M.B. Pinto and J.K. Pinto, J Prod Innovat Manag, 7, $200(1990)$

5. T.J. Allen, D.M. Lee and M.L. Tushman, EM IEEETEM, 27, 2 (1980)

6. K. Jugdev and R. Müller, PMJ, 36, 19 (2005)

7. L.S. Henderson, Int J Proj Manage, 22, 469 (2004)

8. H. Ryynanen, Int J Bus Inform Syst, 11, 324 (2012)

9. S. Wasserman, \& K. Faust, Social Network Analysis: Methods and Applications (Cambridge University Press, 1997) 